\title{
Editorial
}

\section{Editorial: Digesting the Milan Expo, 2015}

Place Branding and Public Diplomacy (2015) 11, 169-174. doi:10.1057/pb.2015.10

Expos are to the fields of place branding and public diplomacy what the Olympic Games are to sports - opportunities to marvel at the state of the art and - if we wish to push deeper - to track trends of emergence or decline and absorb the latest installment of what can be a slow motion soap opera of international image making. This year's Milan Expo mixes the usual fascination of a mega event with the specific concerns of an especially significant theme: 'Food: Feeding the planet, energy for life'. The results are intriguing as ever. I approached the Milan Expo with a clutch of questions in mind. I was keen to see what could be read about the general direction of place branding and public engagement at an expo whose planning and execution have been almost entirely under the pall of widespread austerity. I wanted to glance back to former expos and forward to coming installments of the drama. I wanted to see if it was possible to tease apart the countries that were actually making a difference on the issue of food from those merely talking a good game. I also wanted to seek out the shared themes and the telling details that bring an expo to life and maybe find those most elusive of commodities - heroes and villains - in our shared struggle to feed our planet.

The scale and nature of the contributions to the Milan Expo made it clear that regardless of austerity many countries place immense stock in both expos and place branding, and perhaps are looking to it as a way out of the economic doldrums. The most obvious believer is Italy. Italy invested heavily in the expo not only from the city of Milan and the central government but also from its multiple provinces, which contributed elements to the national pavilion and provided regional cuisine restaurants all along the approach. The extraordinary level of the Italian contribution and the welcome offered by the local expo staff ensured that the host was the 'winner' of the expo. The theme of food was the perfect vehicle for displaying some of Italy's greatest assets cuisine, culture, diversity, tradition and design - if at the expense of Italian technical and engineering excellence which are not as widely appreciated abroad. One important element was the host's attempt to show leadership in environmental issues at what is the first sustainable and carbon neutral expo. Italy emphasized social justice aspects of the theme. The hosts encouraged fairgoers to commit to what was termed the 'Milan Charter' against waste and inequality in global food politics. One left feeling that Italy was not just an attractive country but a good country.

My co-editor Robert Govers and the founder of this journal Simon Anholt have emphasized the importance of goodness as a reality beneath a place brand. It was striking that of the countries which Anholt's Good Country Index has identified as especially 'good', which also showed up at Milan were also among the strongest (www.

goodcountry.org/overall). The Netherlands (\#4 in the index) was dominated by bars and 
eateries but people loved it. Switzerland (\#3) offered a popular and thought provoking pavilion centered on a tower filled with symbolic Swiss food exports: sachets of Nescafe instant coffee, little packets of salt, cups of mineral water and other items. These were free for the visitor to take with the catch that one was invited to be mindful of other guests and that the reserves would not be replenished. The contents of the tower would be consumed during the course of the exhibit and the level of the floor drop accordingly to leave space behind in witness to the resources which had been used up. ${ }^{1}$ Other elements of the pavilion were hardly less engaging including an exhibit on the science of nutrition and a magnificent carved scale model of the Alpine watershed showing how Europe's great rivers originate in Switzerland. Still stronger than the Swiss pavilion was the offering of the Irish Republic - the country at the top of Anholt's Good Country Index - which had both a pleasing exterior and clear message inside. The pavilion - entitled Origin Green - focused on the application of environmental standards to Irish agriculture that require every farm to be inspected on an 18-month cycle for traceability, quality assurance, water conservation, animal health and welfare, pasture management, biodiversity, and carbon emissions. Juxtaposed with engaging panoramas of the emerald isle and cheerful portraits of its inhabitants were captions noting facts that were astonishingly adrift from the state of food production elsewhere, such as that 90 per cent of Irish cows were grass fed. Ireland is well on its way to becoming the first country in the world to have all its food production from 'third party verified' sustainable sources. One cannot but admire, and perhaps wonder if Irish farmers are quite as smiley as depicted given the level of scrutiny of their practices that this requires.

Beside the eloquent presences at the expo one must also place the eloquent absences some of whom included countries identified with the great expos of the past. The most striking absence was probably that of Canada, host of the great Montreal expo of 1967 the Vancouver Expo of 1986. Its absence is blunt testimony to the on-going neglect of Canada's image under the stewardship of Prime Minister Stephen Harper with his 'dig it up and sell it priorities'. Equally remarkable was the absence of Australia (host of Brisbane 1988 and a star turn at the Shanghai expo in 2010 and Yeosu 2012) or Portugal (host of Lisbon 1998). New Zealand was also missing. More than this the entire Nordic region stayed away denying visitors insight into both a distinguished food culture and the wisdom of some of the countries which have thought most about issues of sustainability in agriculture and earned 4 of the top 10 spots in the Good Country index. It is a shame they didn't pool resources to generate a joint space as Finland, Sweden and Norway already do at the Venice biennale. The thematic space usually taken by the Nordics, which one might call 'pine and design', was enthusiastically occupied by the Baltic countries. Estonia did especially well with an open, fun and eclectic wooden pavilion filled with examples of the country's ingenuity past and present. The same eloquent absences were to be found among the food on offer at the expo. As the blogger and cultural diplomat Paul Rockower - coiner of the helpful term gastrodiplomacy - has noted, a number of nations whose place branding has emphasized this element in their culture stayed home. Peru was the gastronomic star of both Shanghai in 2010 and Yeosu in 2012. India and South Africa were also much missed. ${ }^{2}$ Conversely some countries which should have had an excellent gastronomic presence skimped. Thailand was an especially egregious case. The Thais ended a rather tacky pavilion (its climax was a propaganda film about the king) with a shop selling re-heatable convenience food and a bank of microwave ovens. National culinary glory is not won in the microwave.

Of course expos are not read in isolation, but are an unfolding text in which familiar characters return to reveal a little more of an on-going story. One of the most obvious stories of recent expos has been the struggle of the United States to put on a good show. The United States was a no-show at Hanover in 2000 and - as the new documentary film 'Face of a Nation: What happened at the World's Fair'? by the American architect Mina Chow makes clear - nearly fumbled its contribution to Shanghai in 2010. The US 
pavilion in Yeosu was better, and it is good to report that the pavilion in Milan - Food 2.0 - was certainly among the best. As ever, the US pavilion's student guides were a terrific resource. The pavilion had its wonders - a field of crops mounted vertically along one exterior wall and a water curtain in which patterns and messages appeared; it had its welcoming video messages from the president, first lady and secretary of state; it had its roof garden and bar, its engaging displays about food problems and solutions, and it had a good walk-through movie about American food culture which showed the country's regional and ethnic diversity. The succession of families each enjoying Thanksgiving turkey but with their own ethnic twist was especially true to American life. The flaw was unexpected. One of the most celebrated trends in American food of late has been the emergence of the food truck (check out the movie Chef for dramatized version of the trend) however rather than importing genuine American food trucks for the 'Food Truck Nation' display the pavilion team converted European trucks and simply approximated the experience. This element did not seem to be a hit, unlike the genuine Dutch food trucks doing a roaring trade as part of the complex of installations that made up the fun Netherlands pavilion.

Of other evolving expo stories the recent and upcoming hosts delivered strong contributions China, Germany and the host of Dubai expo 2020, UAE, were all impressive in both their architecture and content. China's undulating roof was one of the wonders of the expo. Germany's 'Field of Ideas' theme was an obvious extension of its 'Land of Ideas' brand. UAE shone with a remarkable building by Norman Foster and content that was a favorite with the crowds. As in both Shanghai and Yeosu UAE's pavilion was built around a show in which a child narrator discovers their country and the world. In Yeosu the pavilion seemed to touch on the theme of 'people power' as the boy protagonist was shown starting a mini Arab Spring civil movement to ban plastic shopping bags. ${ }^{3}$ In Milan the story flirted with the prospect of a girl and her grandmother chaining themselves to a special palm tree in defiance of a construction team until the girl's father arrived in his helicopter to airlift the tree to safety at their out-of-town villa. It was not a solution available to every tree-loving urbanite. Japan - host of Aichi, 2005 - was visually engaging but perhaps a little too idiosyncratic, revealing a growing problem in Japanese public diplomacy of playing to domestic tastes with insufficient regard for foreign sensibilities. There was also a complacency to the Japanese offering. In an animation sequence a big woodland spirit tells a little woodland sprit not to worry about the environmental crisis. It was bound to be fixed. That is not a helpful message on the eve of the vital Paris climate summit when public pressure is essential to push governments to act. Of the runners up in recent bids to host expos Russia made a strong contribution and won friends with plenty of free samples. Turkey looked good but was fragmented: a feature of Turkish politics at the moment. The contributor on a clearest up-swing was Kazakhstan - host of the up-coming energy expo in Astana in 2017. The Kazakh pavilion managed to be both fun and informative. We moved from a room in which an artist created projected images of Kazakh history in real time on a sandbox, through a series of displays recreating landscape and vegetation, and on to an exhilarating ride in a $3 \mathrm{~d}$ flight simulator ride over the country. There were free samples of the national drink (which guests may not have realized was fermented horse milk) and a sobering look at the disappearance of the Aral Sea, one of the most outrageous ecological disasters of our time. The restaurant rounding things off nicely: those who enjoyed the horse milk were welcome to eat its source on toast. The whole experience augured well for 2017.

While expo pavilions are generally based around big concepts they rely of getting the details right. Some of the strongest pavilions in Milan were compromised by simple design flaws. The most striking example was in the South Korean pavilion where guests where marshaled by uniformed young Koreans speaking through tiny loudspeakers strapped to their belts. The level of distortion was so great as to make it hard to tell if they were speaking Italian or English and definitely unpleasant to be around. Many pavilions 
had interactive displays which lagged or had ceased working. The Brazilian pavilion's screens were too dim to read with the pavilion's high light levels. Conversely there were those simple pavilions which got the concept and details right and sometimes with basic technology. The pavilion created for the NGO Save the Children was an especially good example of this, working with well-trained guides and well-chosen examples it showed how well properly conceived development projects could make a real difference.

Some pavilions had telling details which reflected well on the country: a vivid work of art, a moment in the presentation or an especially well-considered element of architecture. The Latin American pavilions all shone in this regard: their special efforts in Milan motivated in part by ethnic ties between Italy and major historical immigration destinations in the New World. Argentina looked to the past commenting on the migration experience with an amazing wooden machine in which cut outs of people traveled into their new country on a conveyer belt. Ecuador was a riot of tropical color, especially after dark. Chile - as usual the strongest from the region - had a stunning exterior built from renewable timber and awesome scenic displays inside. Uruguay offered a movie in which an old immigrant remembers the past and talks to his granddaughter about the virtues of the country with its strong state education system (one laptop per child) and a commitment to diversity. The final montage included a gay couple, ${ }^{4}$ which rather pointed the degree to which many counties abandoned any sense of contemporary diversity to focus only on a traditional pluralism based on the range of cheese or artisanal dinner rolls available. The movie seemed long but it did its job and by the end I certainly felt real warmth for Uruguay, though it might have been Stockholm syndrome kicking in. Colombia was doing well with a fascinating introduction to the geographical diversity of the country but blew it for me with an interminable final music video featuring local singers gyrating and lip-syncing in various Colombian beauty spots. It did not help that the pavilion made little attempt to present materials in any language other than Italian.

If hi-tech let some pavilions down there were others which made excellent use of the lowest of 'techs': strategically positioned plants and vegetation. The entire Austrian pavilion was a forest, transplanted to Milan to illustrate the ability of trees to generate oxygen. Unlike a real Austrian forest it also contained a rather nice snack bar with a good line in meatballs and roast root vegetables. The combination of gardens and restaurants within so many pavilions added an unusual detail to the experience of the Milan Expo: smell. The French and Polish garden's both smelled wonderful as did several of the Middle Eastern pavilions - Morocco and Bahrain particularly. There was one use of smell to underline a negative. A side area of the Save the Children pavilion included a smell of oil and burning - the 'smell of war' - added to dramatize the refugee experience.

One of the oddities of expos is the tendency of 'great minds' to 'think alike' and for particular themes to emerge in multiple pavilions. In Shanghai there were a dozen national pavilions evoking the silk road and heritage of trade between east and west. In Yeosu, with its ocean conservation theme, a number of countries featured manatees. At Milan there were a number of examples of clustering: the United States, Angola, Israel and some others created vertical gardens. Several countries hit on the idea of representing agriculture as a man and science as a woman with a test tube. She figured like a latterday Jungian architype in half a dozen movies, illustrations and static displays. The EU built its entire contribution around several installments of an computer animated love story between a farmer and lady scientist who met through their dogs, made it through the rain (which was actually sprinkled into the auditorium) and went on to win a baking competition. Though I liked the story in spite of myself, I found myself asking whether this was really the best way for the EU to dramatize its vision and relevance to the future? Was this what Ukrainians were protesting to join last year? The tiny audience was unamused. No one took the free posters celebrating the show at the end of the 
experience. But in Milan one shared element rose above all the others: the bee.

As many pavilions made clear: people are proud of their beekeeping. Angola, Jordan and Greece mentioned it and Save the Children showed it as a development project. Germany's concluding show was bee themed with visitors urged by a duo of an energetic guitarist and beat-boxer to 'bee active'. Malta - the island of honey production and rock color, which actually got its name from the Greek word for the product melite - and Slovenia - home to the most important European bee species made bee keeping the central element in their pavilion. Both built honey combs into their interior design, which would have been impressive were it not for the UK pavilion. The UK pavilion was complex - a delicate skeletal cube structure at the end of a garden - and loaded with symbolism. At the entrance was a sign reading 'the UK is a hive of innovation and creativity, helping to feed the planet', and a logo of a lightbulb with a yellow silhouette of a bee hive in place of the filament. The pavilion path was zigzagged and sunken to give the impression of a bee's eye view and flightpath as one approached. The structure was electronically linked to a bee hive in the British countryside and changed during the day to reflect the bees' mood and activity. At the center of the pavilion structure was a spot where a visitor could stand and through the magic of acoustics listen to the world through vibration in the same way as a bee. The value of the bee went beyond the nutritional value of honey or historical value of beekeeping. The bee presented the ideal vehicle for demonstrating the interconnectedness of the ecosystem and, moreover, the dangerous decline of bee populations worldwide - essential for the pollination of 30 per cent of crops - provided exhibition designers with one of the most troubling signs of that ecosystem's worrying fragility.

Expos are all about stories, and every good story needs a villain. Most pavilions defined themselves in the abstract against trends and dangers: climate change, food insecurity and inequality. Some were prepared to go further and talk not just the problem of those without, but of those with too much. UAE and a number of others raised the issue of obesity. The French explicitly engaged what it described as the obesity epidemic. An animated film inside the pavilion noted that France had one of the lowest rates of obesity in the world and suggested that the variety within the French diet might have something to do with that. More than this the French film gave a strong hint who might actually be to blame as giant hamburgers and a leg of fried chicken were shown rampaging through a city like Godzilla, zapping people with obesity rays. There were no flags involved, but the implication was clear. For those who missed the point it was a short walk to the McDonalds restaurant in between the pavilions from Qatar and Turkmenistan.

Expos by their nature try out new practices some of which stick and become regular features of future events. Expo '67 in Montreal introduced the passport which fairgoers could get stamped at each pavilion. The big innovation at Milan was the thematic pavilions which grouped smaller countries not by region but by a shared element of their diet or agriculture. Hence there were buildings or areas labeled rice, spice, cereals and tubers, coffee, chocolate and so forth. The Mediterranean has its own area perhaps understandable given the recent recognition by UNESCO of its diet as part of the intangible cultural heritage of the world. It will be interesting to see if the grouping experiment will be thought a success. Few of the constituent pavilions had visitors; most were like airport gift shops blended with snack bars, but they gave counties the opportunity to say they were involved and some hit their mark. Malta was charming and a lot of people went to Cuba to get drunk on rum. The coffee area not only had a terrific aroma but also featured giant photographs by the Brazilian photographer Sabastião Salgardo of coffee production around the world, maintaining the tradition of expos as places were art works are premiered.

The importance of the central theme of the global food supply is such that in the last analysis it is less important which contributions worked and which fell short than what the whole exercise may be said to have contributed to the collective effort. Perhaps it was a sign of the times or the collaborative nature of cooking that whereas in Shanghai pavilions seemed to celebrate unilateral excellence in Milan there was an emphasis on a 
team effort to address the problems facing the world. The Vatican had its own pavilion extolling the virtues of social engagement and UN installations could be found in many places throughout the expo. Of course there were excellent ideas for renewable energy, improved efficiency, safety and - a priority for many consumers - traceability, but it was the willingness to listen, learn and collaborate that seemed to predominate and frequently to trump a narrow desire for national recognition. This was good to see. In the last analysis we must all build not just the reputation of a small place but the reality of the place we all share, and that reality - as it stands - is shamefully compromised by inequality and alarmingly vulnerable. The Milan expo left me feeling there may yet be hope.

\section{NOTES}

1 The idea of a consumable exhibit echoes the Angolan pavilion at the 2013 Venice Biennale of art as noted in my editorial in Volume 10, issue 1, 2014.
2 Paul Rockower, blog: 'Expo Milan 2015: The good, the bad and the hungry'. 8 June 2015 on line at http://uscpublicdiplomacy.org/blog/ expo-milan-2015-good-bad-and-hungry.

3 The UAE's Yeosu film may be viewed here https://www.youtube.com/watch? $\mathrm{v}=\mathrm{Hu} 1 \mathrm{jsC} 1 \mathrm{tq} 8 \mathrm{Q}$.

4 The inclusion of a gay couple was not mere window dressing. Uruguay has led its region in LGBT issues. On 1 January 2008 it became the first Latin American country to legalize samesex civil partnership. In August 2009 it became the first in the region to allow joint adoption. Uruguay has had equal marriage since 2013 (following Argentina in 2010 and Brazil earlier 2013). I appreciate the help of Carissa Gonzalez formerly of the US embassy, Montevideo for drawing this to my attention.

Nicholas J. Cull University of Southern California, Los Angeles, USA E-mail: cull@usc.edu 